\title{
Smart overbooking in the accommodation facilities in the Czech Republic
}

\author{
Jiřina Jenčková \\ University of Economics \\ Prague, Czech Republic \\ jirina.jenckova@vse.cz \\ Josef Abrhám \\ University of Economics, \\ Prague, Czech Republic \\ josef.abrham@vse.cz
}

Abstract. Overbooking can be defined as a targeted, planned and managed overbooking of the capacities available in the way that at a given date there is no conflict between more clients and simultaneously the capacity is optimally used so that the revenues are maximized. The main prerequisites for the application of the overbooking techniques are a sophisticated hotel system and the ability to predict the strength of demand for accommodation facilities. The aim of this paper is to analyze the state of the implementation of the method of "smart overbooking" as used in practice by the Czech accommodation facilities. The focus is placed on finding out the level of the awareness of this tool, its deployment and the extent of its use as well as the clarification of potential problems with the implementation. The methodological approach to solution-seeking is based on the results of its own survey of more than four hundred hotel facilities in the Czech Republic.

Keywords: overbooking, smart overbooking, dynamic pricing, revenue management, demand forecast, Czech Republic

JEL Classification: L83, L89, M21

\section{INTRODUCTION}

Even though the average occupancy of the accommodation facilities increases slightly every year, the Czech Republic is still below the optimal values of the beds usability. To achieve higher occupancy, various management techniques are available. One of them is targeted overbooking (so called smart overbooking). This method was introduced by airlines, whose customers often fail to check in and the aircraft remain partially vacant. Currently the technique is commonly used in the hotel industry, too. An overbooking can be defined as the management of rebooking the available capacities at a given date where there is no conflict between more clients and the capacity is optimally used so that the revenues are maximized. Within this 
strategy a very strong emphasis is therefore placed on the prediction of the future demand and the development of booking.

The aim of the paper is to evaluate the current state of the application of the method of Smart Overbooking in the Czech accommodation market. The stress will be placed on finding out the level of the awareness of this tool, its deployment and the extent of its use as well as the clarification of potential problems with the implementation. The methodological approach to solution-seeking is based, in the theoretical part, on the results of the review of the analysis of domestic and foreign literature and published research studies. The basis of the practical part creates an analysis of the results of a survey of more than four hundred hotel facilities in the Czech Republic.

\section{LITERATURE REVIEW: SMART OVERBOOKING AS A REVENUE MANAGEMENT TECHNIQUE}

Maximizing capacity utilization, and hence the revenues, is one of the tasks of a revenue manager. The purpose of the revenue management is to proceed in such a way so that the accommodation capacity is optimally exploited at the highest price attained. This should lead to a high level of the revenew per available room (RevPAR) achieved. The shares of the development of individual market segments, the values of RevPAR and GOPPAR can be considered as key indicators that the management follows. An inseparable part of the revenue management is so called yielding (yield management), the aim of which is to maximize revenues while effectively handling the capacity and the dynamics in price. This method is characterized by the fact that it can be used only for the services that the customer ordered or paid in advance, with a limited (constant) capacity and a high proportion of fixed costs. The basis of the method is the investigation and analysis of the demand (and its variations), so-called „demand forecasting“. This is a qualified estimate of the demand in combination with a daily yielding.

A prerequisite of modern management methods is a work with data sources that revenue manager receives from the Property Management systems (e.g. Previo, Protel, Fidelio, Opera, HotelTime, Mews, Mephisto, Hores, etc.). Without a hotel management system of good quality it is not possible to predict the development of the demand.

As the basis for yield management have been defined so called „4C" of the yield management (Enz, Withiam, 2001) which are Calendar, Clock, Capacity and Cost. These are four tactics that can be applied to achieve the goals set. To make a theory complete, it is possible to add the fifth "C", which represents the fifth pillar - Customer.

The calendar monitors the date of the reservation/booking of the service, the clock provides the time of its delivery, while the balancing of the capacity during peak periods and periods of a reduced demand takes place and eventually the cost is set, which is advantageous for service providers and acceptable to the customer (Enz, Withiam, 2001). In order to apply these tactics it is necessary to follow certain rules and to define correctly the basic parameters (service, customer, price, and terms of provision). These rules can also include the best estimate of the demand curve using the threshold curve, which shows the number of bookings for the past three months. If the number of bookings declined and got below the average threshold curve, the revenue manager could launch lower price tariffs and the demand would increase again. On the contrary, when there were be more bookings than expected, sales of low-price tariffs would be ceased and only lucrative bookings would be accepted to avoid overbooking. 


\section{METHODOLOGY}

Some tourism businesses use overbooking consciously. This method was introduced by airlines, whose customers often fail to check in and the aircraft remain partially vacant. A similar problem also resolves the managers in the hotel industry. The technique of overbooking shall prevent from unused capacity. Overbooking pursuits to prevent the collision of more clients and is rather focused on achieving the optimal capacity utilization while maximizing revenues. A real move of the guest to a substitute accommodation should be a rare issue. It is a technique, the ethics of which is fiercely discussed, particularly in cases where the overbooking is inappropriately applied. With this strategy a very strong emphasis is put on the prediction of the future demand and the development of booking. A forced move of the clients to substitute accommodation facilities due to the overbooking is, in general, negatively reflected in the reviews and trust of the customers. The performed survey showed that almost $80 \%$ of the guests never arrive again to an overbooked hotel, and fewer than $45 \%$ provide a negative review on the relevant portals. Moving due to the overbooking is harder to be accepted by men. $57 \%$ of those who have left negative reviews are male (Short, 2014). Negative impacts can be minimized through a good organization, an offer of the accommodation of better quality and through additional services. Short (2014) claims that most migratory guests expect a little bit more than a (qualitatively) same room located at a nearby hotel. Almost a third of respondents understand a comparable room as the absolute minimum, 30\% would appreciate a little extra and only $27 \%$ would have been perfectly satisfied. If we consider the consequences of the financial compensation, half of the respondents would be willing to go back if the stay was for free. In case of the same compensation, the same number of guests would not provide negative reviews. Given the cost of a guest, the stay for free is considered as the most effective way of compensation. Lost customers and negative reviews bring about for the hotel considerably worse economic impacts (Niemczyk, 2014, 2015; Short, 2014; Streimikiene \& Bilan, 2015).

The calculation of the optimal level of overbooking is simple from a methodological point of view. An intricate component is the ambiguity of some inputs. It is difficult to predict future developments. Historical data serve as a useful indicator of the likely development, but cannot be understood as absolutely valid values. Tourism is highly variable and the behavior of tourists is almost unpredictable. The information that is available without a doubt, is the average daily cost per room (ADR $=$ average daily rate) and variable costs per room. The third variable in the calculation of the ideal ratio of overbooking is the cost of moving a guest that needs to be estimated on the basis of previous experience or calculated in accordance with the type of the compensation (Kimes, 2013). To calculate the cost of overbooking, it is necessary to know the cost of the empty room, cost of moving a guest and the likelihood of the unrealized guest bookings for individual months and days of the week. The mentioned data can be processed through the hotel systems. Such data are part of the portfolio of traditional Property Management System, but also RMS - Revenue Management System as well as of some specialized programs, such as future forecasting programs.

\section{IMPLEMENTATION OF THE SMART OVERBOOKING IN THE CZECH REPUBLIC}

The following text will resume the current state of the deployment of the Smart Overbooking method in the booking practice of Czech accommodation facilities. As the database is used a questionnaire survey carried out in the period from June to August 2015. Over 500 accommodation facilities were addressed, mostly three-star and four-star hotels of the size of at least 20 rooms and 40 beds. A complete set of data was obtained from 147 utilities. The questionnaire survey contained 26 questions. The sample consisted of $83 \%$ of hotel facilities, nearly $11 \%$ of $\mathrm{B} \& \mathrm{~B}$, as well as apartments and resorts. A third $(32.5 \%)$ of the facilities 
have 25 rooms ( 50 beds), $15 \%$ of the respondents have between 26 and 50 rooms (100 beds), a fifth (19.3\%) of the respondents between 50 and 100 rooms ( $200 \mathrm{beds})$, the second one fifth $(22.9 \%)$ of the respondents between 100 and 250 rooms ( 500 beds) and less than $10 \%$ of the respondents have a capacity of more than 251 rooms (over 501 beds). Regarding the classification of the accommodation facilities, most representatives of the respondents have a three-star accommodation facilities (37.3\%), followed by a small class of high category $(32.5 \%)$.). The four-star-plus category is represented by $18 \%$ and the five-star and five-star-plus make $13 \%$. According to the portal hotelstars.cz only $36 \%$ of the respondents are certified. The majority of subjects $(71 \%)$ are not part of the hotel chain or a hotel group. Almost $52 \%$ of the participants surveyed operate in Prague and the Central Bohemia region (which rather follows the situation in the first article and in general - as claimed in terms of the upselling - those that have an active interest in the developments in the field), $11 \%$ of the respondents came from the Karlovy Vary and the South Moravian regions and the remaining $26.5 \%$ of the respondents are evenly divided in the remaining regions except fort the Olomouc and Usti regions, which did not participate in the investigation. Moreover, it appears that $13 \%$ of the respondents in this survey do not use any hotel system. Among the most widely used systems belong Micros Fidelio and Micros Opera systems mentioned by $25 \%$ of the respondents. In addition, we can come across the systems such as HotelTime, Previo Hores Plus, Protel, but also Mews, Agnis, ComArr, Rehos, Savarin, Mephisto and Laurin. On the other hand, the vast majority (84\%) of the respondents do not use any other support system, or revenue management system. If they do, the most frequently mentioned one was the Revenue Management System developed by the IDeaS company.

The follow-up questions were focused directly on the issue of overbooking. $56 \%$ of the respondents work in accordance with the principles of the revenue management, it means they strive for optimal yield lodgings, however in relation to the maximum average price. $26 \%$ of the subjects aim for a maximum occupancy of their accommodation capacity, $13 \%$ of them are struggling with the insufficient demand, and only $5 \%$ of the subjects applied „smart overbooking “in the phase of the incoming bookings. Thus the result is 18 subjects with the average occupancy for the year 2014 in the amount of 70-80\%, 17 subjects had 60$70 \%$ occupancy, five respondents stated $80-95 \%$ and only one representative achieved $90-95 \%$. All other respondents were below $50 \%$ occupancy.

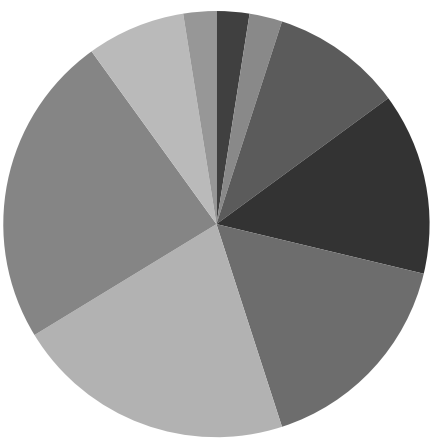

\begin{tabular}{|c|c|c|c|}
\hline $5 \%$ & $25-30 \%$ & $-30-40 \%$ & $40-50 \%$ \\
\hline $60-70 \%$ & $70-80 \%$ & $80-90 \%$ & $90-95 \%$ \\
\hline
\end{tabular}

Chart 1: Average occupancy rate in 2014

Source: Own results. 
Mostly, there were fifty days (27\%) called „fill days“ which can be understood as „the number of days when the occupancy exceeded $95 \%$ " in $2014.19 \%$ of the respondents reached up to 20 fill days and $16 \%$ facilities achieved 30 and 70 fill days, respectively. The range of $71-100$ fill days was reached by $12 \%$ of the respondents and one participant even said that he managed to reach 236 fill days. $7 \%$ of the respondents reached up to 10 fill days in 2014.

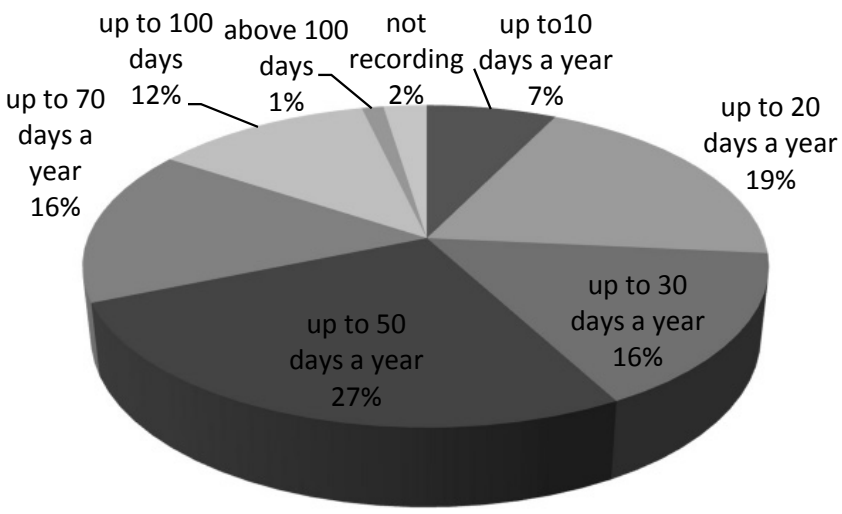

Chart 2: Number of filled days in 2014

Source: Own results.

The estimates of the capacity for the year 2015 are optimistic $-65 \%$ of the respondents believe that the occupancy will be higher than in 2014. Most commonly is expected a growth between 3-5\%. This is related to the expected development of ADR (average daily rate) in which the majority of the respondents (58\%) expect an increase (5-10\%). Approximately one third of the subjects, however, believe that neither ADR nor the capacity will change in 2015 .

$41 \%$ of the subjects reported to have a precisely calculated (and proven in practice), the percentage of targeted overbooking, and another $11 \%$ have a so-called „safe percentage“regulated thanks PMS/ RMS. Other operators in the survey do not know by how much they can rebook the capacity or they do not use this method at all (as many as $50 \%$ of the respondents).

The impact of the overbooking on revenues in some cases (approximately $40 \%$ of the respondents) is difficult to be substantiated and calculated. Despite of that, $27 \%$ of the subjects agree that this method has led to an annual increase in their revenues in the range of up to $20 \%$. Correspondingly, $27 \%$ of the respondents stated that they overbook from the beginning. Then, the question put should rather have been: what would be the revenues if rebooking was not used data all?

The impacts on the clients are minimal according to the survey, since over $60 \%$ of the surveyed organizations use „smart overbooking“ and therefore almost no forced move of the guests had to take place. The respondents agree that the moves occur only in case of the human factor failure. $23.5 \%$ of the subjects in 2014 did not have to move a single guest. One move of the guests appeared with $12 \%$ of the respondents. 30\% of the respondents reported maximum 5 cases of the move, most frequently in 10 rooms (35\%). Only $5 \%$ of the respondents stated that there was a move of the guests more than 20 times in 2014 . 22\% of respondents did not have to move even one guest, while about $7 \%$ of those surveyed last year had to change more than 50 rooms. 


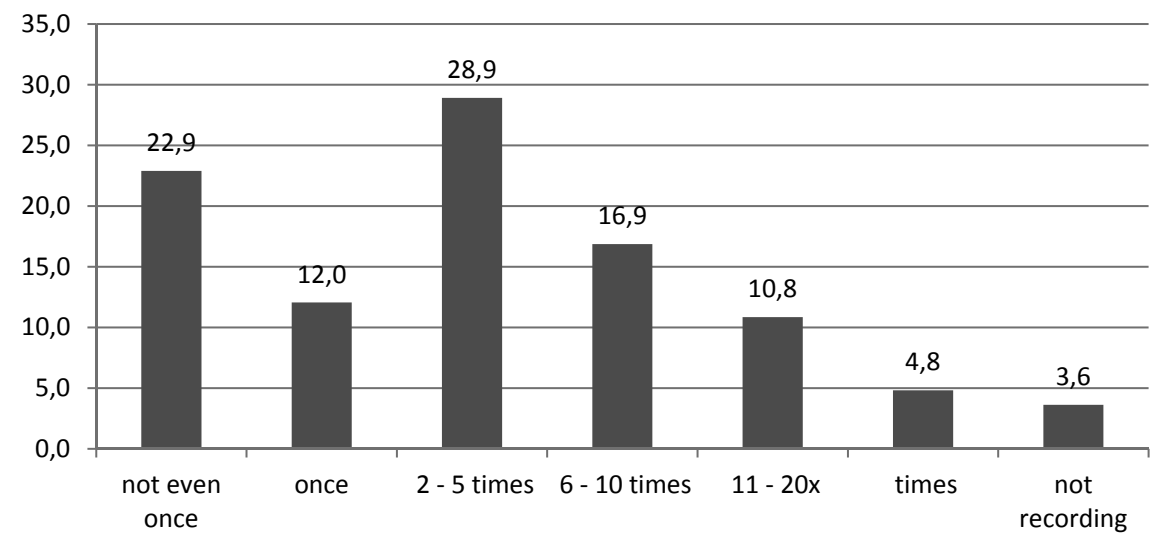

Chart 3: Number of overbooks in 2014 (in \%)

Source: Own results.

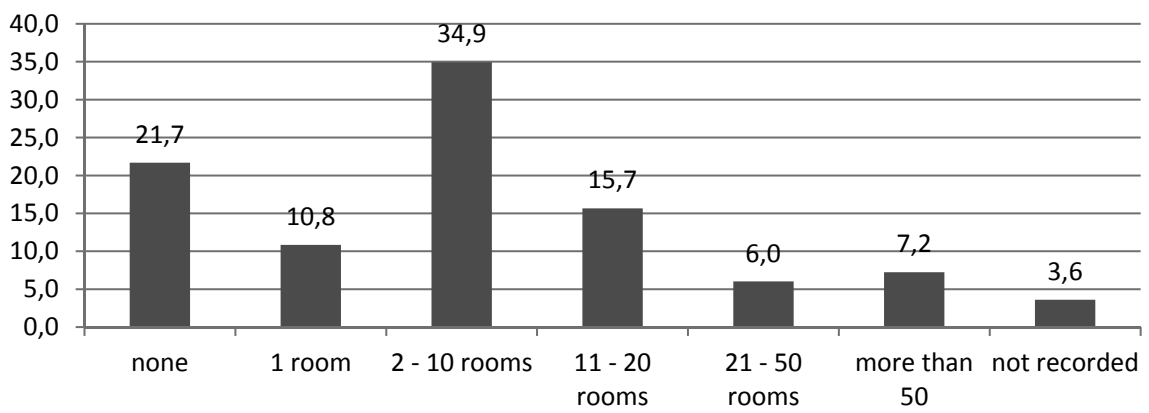

Chart 4: Number of guest walk-outs in 2014 (in \%)

Source: Own results.

So why, for the time being, do not hotels standardly use the „smart overbooking“? The most frequently reasons cited were, for example, that subjects cannot effectively work with rebooking or that they do not know „the safe percentage of overbooking“, or the facility with a very low demand was in question. Further $6 \%$ of the subjects are forbidden, by their management, to apply overbooking. However, nearly $60 \%$ of them find no obstacles in the overbooking. 


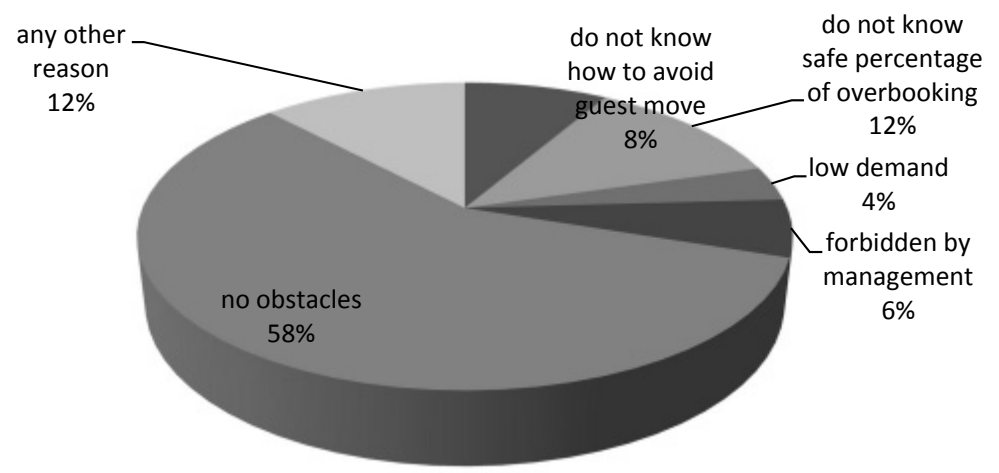

Chart 5: Obstacles to use "smart overbooking"

Source: Own results.

Neither the so called „group replacement", which means replacing less profitable groups for those more lucrative does not belong among conventional techniques for the moment. More than $60 \%$ have never used it and another six percent do not even know the term "group replacement“. In 26 cases they use the method but quite rarely.

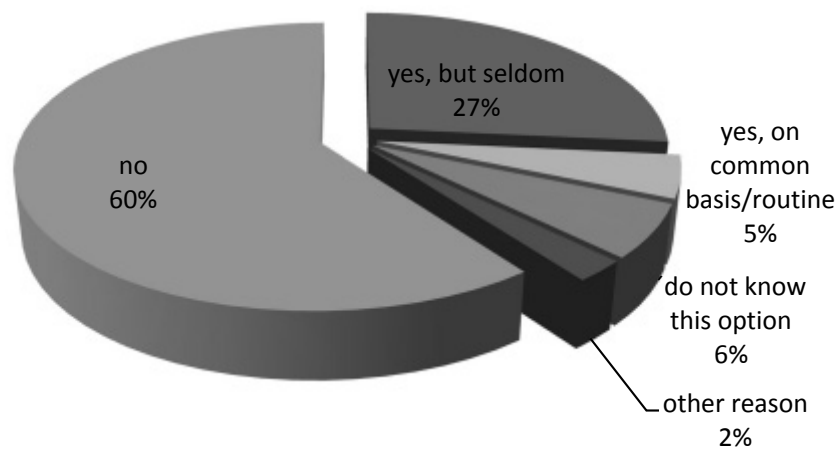

Chart 6: Using "group replacement" (in \%)

Source: Own results.

If a higher capacity than $95 \%$ fill days is expected and the associated probability of exceeding the $100 \%$ level occupancy on the day of the arrival, accommodation facilities most often (70.7\%) focus on that very date from the view of recognizing potentially a significant day with the anticipated higher level of demand (such as holiday, congress, sport event, vacation, etc.). 68\% of the respondents monitor the composition of the bookings, whether it is a guaranteed booking assured by advanced payment via a credit card or prepaid, or non-guaranteed bookings which the guest may cancel at any time and, in the case of no-show he is not charged any cancellation fee. Furthermore, the respondents most often watch (48\%) both the same term last year (and its development) as well as how the situation evolved overall. Approximately $40 \%$ of the respondents follow the developments of the competitors and its own rate of the cancellations and no-shows. 18\% 
of the respondents know the number of walk-in guests. Only a third (32\%) of the respondents know and follow its usual percentage of the increase in booking, so called pick-up for the given period. More than $20 \%$ of the respondents have, in case of similar situations, preventively agreed conditions for the removal to the competing hotels. Only one of the surveyed organizations relies on the waiting list.

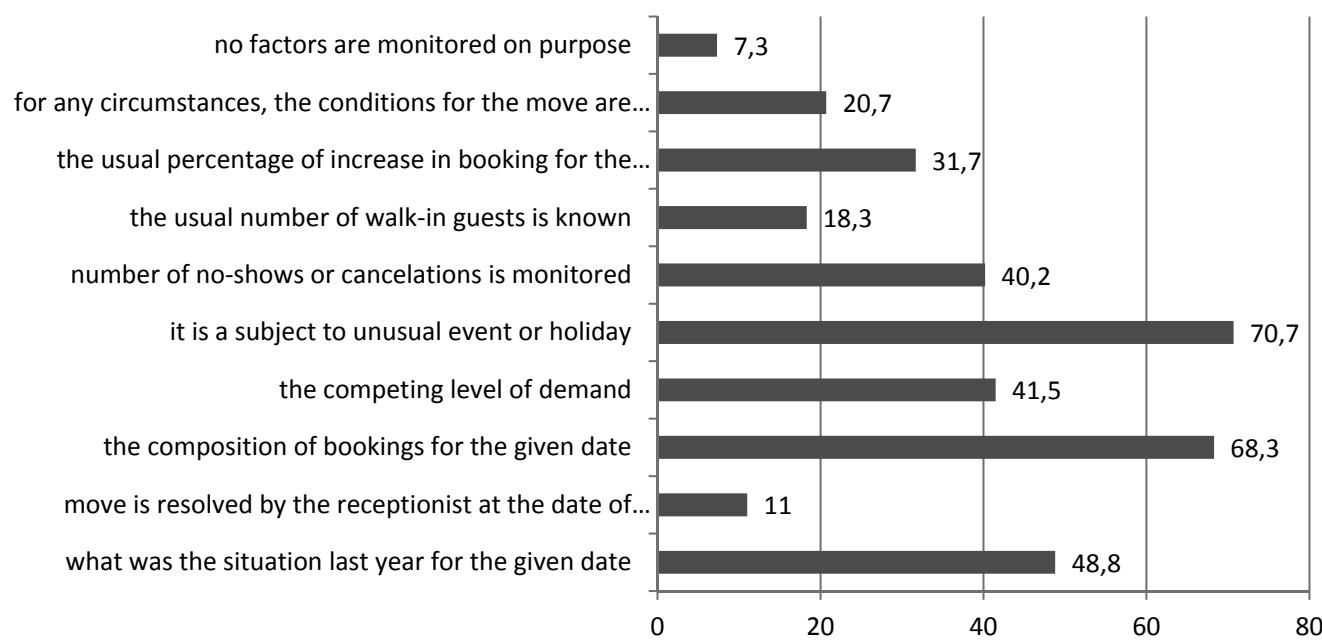

Chart 7: Relevancy of the factors in time of high demand expected „fill days“ (\%)

Source: Own results.

If it is no longer possible to avoid moving a guest, a majority of the accommodation facilities offer hotels of higher quality with extra benefits. So that there is no loss of guests or partners - regular guests and business partners are principally not moved. $30 \%$ of the respondents have a clear strategy for case of moving and everyone involved knows his responsibility. Conversely, 33\% of the subjects deal guest-moving operatively, without a predetermined procedure.

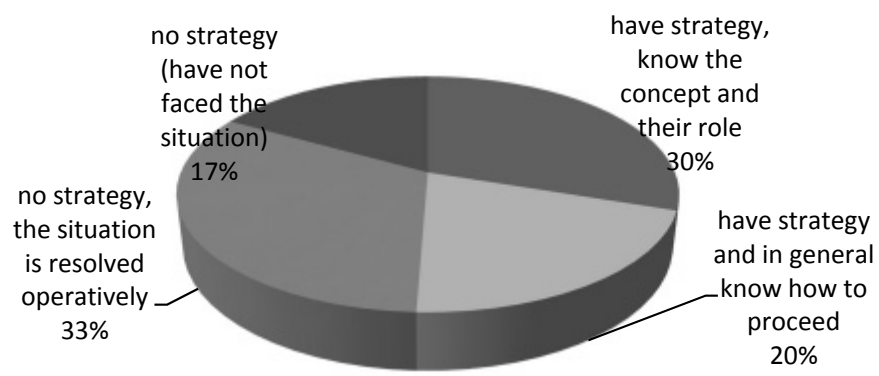

Chart 8: Answer concerning the readiness strategy to move guests Source: Own results. 
Staff training for these situations is used by almost $60 \%$ of the respondents. Nevertheless, there still remain $40 \%$ of the subjects that do not educate their employees in this field. The employees allegedly receive relevant information just before the guest's arrival or the situation is resolved by a booking department or possibly by a responsible manager.

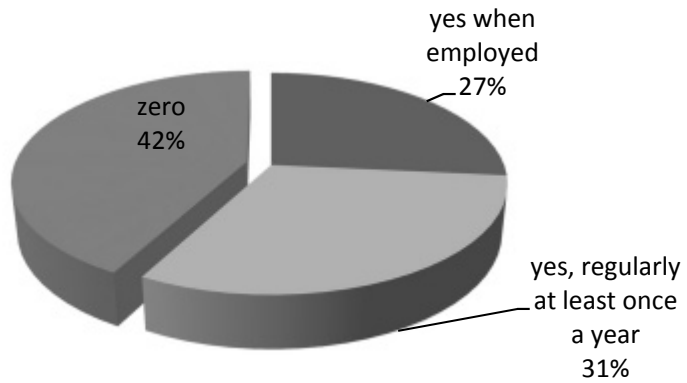

Chart 9: Rate of receptionist trained on smart overbooking Source: Own results.

The results of the study show that the hotels, which keep the average daily rate (ADR) slightly above their competitors have higher revenue per available room per available (RevPAR). The data also proved that price fluctuations did not significantly affect availability. Conversely, it can be observed that hotels with lower prices (compared to the competitors) have a lower availability. A strategy of lower prices may slightly increase the average occupancy of the hotel, but it has a very negative impact on the RevPAR. The highest revenue per room available achieve hotels with the highest average price of accommodation compared with the competition. It is therefore reasonable to assume that customers are seeking services of better quality in case of higher prices. The pricing strategy with higher prices compared with the competitors is, according to the study, more favorable for hotel chains. Within the surveyed sample of the hotel facilities, a relevant relationship between fluctuations in total income has not been confirmed. The total RevPAR is highly dependent on the type of the hotel, to a slight extent on the pricing plan and as already mentioned, it is totally independent of the price fluctuations. Overall, it can be summarized that the revenues are more derived by the ADR rather than from the occupancy. In this regard, one may recommend to minimize large fluctuations in prices and to take greater courage in setting higher prices. However, hoteliers should also take care to ensure that services meet the level of prices and the hotels do not underestimate the predictions of the future development and the use of dynamic pricing.

\section{CONCLUSIONS AND POLICY IMPLICATIONS}

The research conducted showed that overbooking is not currently a fully automatically neither commonly used technique in all types and sizes of the accommodation facilities. Overbooking is deemed as an advanced technique of the portfolio of revenue management. At the beginning, smaller hotels and guesthouses are usually cautious to this technique because of their size and the location. Other facilities, on the other hand, offer such unique services so that the migration of the guests is not possible, since in the vicinity there is no adequate competition. Conversely, those who commonly use overbooking are convinced that this is an essential part of their business strategy. Any increased cost associated with moving the guests are 
multiply offset by the extra revenue gained from increased occupancy and often the average prices. In any case, this technique has a positive impact on higher RevPAR. In any case, we must bear in mind that the goal is to increase revenues, but not primarily to increase the number of the clients moved.

The comments received during the survey clearly show that expertise at this level is not much deployed on the Czech market. The vast majority of the respondents failed to complete the questionnaire. It is highly likely that the reason was their inability to answer certain types of questions. Thus it can be concluded that they do not monitor nor do have the technical capabilities and management skills to obtain such data. The most frequent reason reported in the survey was that the utility cannot work with overbooking or does not know its safe percentage of the overbooking. The application of appropriate tools and methods, however, is an essential part of the daily operation of accommodation facilities as well as of rising an average occupancy and prices, so it seems appropriate to increase the utilization rate of the smart overbooking technology in the Czech Republic. Based on the results of the research one can claim that those accommodation facilities that use smart methods of overbooking, managed to increase both their occupancy as well as the average prices, which led to a positive impact on the financial results of those companies.

Maximizing revenues in tourism business is a daunting task that requires experienced professionals focused on revenue management, software quality, knowledge of the competition, perfect work with historical data and the ability to predict the future developments. A lack of revenue managers need to be compensated by training and education of the experts out of their own staff, who are very familiar with the company and have all the qualities to become a good revenue manager.

\section{REFERENCES}

Colliers International Australia: Hotels Research and Forecast Report. First Half 2015 [online]. [Accessed 2015-05-30]. Available at: https://www.colliers.com.au/Find\%20Research/Hotels/Hotels\%20-\%20First\%20Half\%202015

Enz, C. A., Withiam, G. (2001). CHR Reports: Yield Management. Available at: https://www.hotelschool.cornell.edu/chr/ pdf/showpdf/717/chr/research/yieldmanagement.pdf

Enz, C. A., L. Canina a J., Van Der Rest, P. (2015). Competitive Hotel Pricing in Europe: An Exploration of Strategic Positioning [online]. New York: Cornell University. Available at: https://www.hotelschool.cornell.edu/chr/pdf/ showpdf/4539/chr/research/enzcaninavanderrest.pdf

Global hospitality insights: Top thoughts for 2014 (2014). Available at: http://www.ey.com/Publication/vwLUAssets/EY_-Global_hospitality_insights_2014/\$FILE/EY-Global-hospitality-insights-2014.pdf

Christ, S. (2011). Operationalizing Dynamic Pricing Models Bayesian Demand Forecasting and Customer Choice Modeling for Low Cost Carriers. 1st ed. Wiesbaden: Gabler.

Ideas (2015). The IDeaS Forecasting Management System [online]. [Accessed 2015-06-14]. Available at: http://www.ideas. $\mathrm{com} / \mathrm{en} / \mathrm{software-services/software/ideas-forecasting-management-system}$

Herget, J., Petrů, Z., Abrhám, J. (2015). City branding and its economic impacts on tourism, Economics and Sociology, Vol. 8, No 1, pp. 119-126. DOI: 10.14254/2071- 789X.2015/8-1/9

Kimes, S. E., Rohlfs, K. V. (2005). Best-available-rate Pricing at Hotels: A Study of Customer Perceptions and Reactions. New York: Cornell University.

Kimes, S. E (2008). Hotel Revenue Management: Today and Tomorrow: Cornell Hospitality Report.

Kimes, S. E. (2010). The Future of Hotel Revenue Management: Cornell Hospitality Report [online]. [Accessed 201505-30]. Available at: https://www.hotelschool.cornell.edu/chr/pdf/showpdf/1535/chr/research/kimesrmfuture.pdf

Kimes, S. (2015) The Cheapest and Best Approach to Overbooking: Step-by-step guide to overbooking. Cornell University [online]. [Accessed 2015-06-07]. Available at: http://thehospitalityblog.ecornell.com/wp-content/uploads/2013/04/Overbooking-step-by-step-.pdf 
Klein, R., Steinhardt, C. (2008). Revenue-Management Grundlagen und mathematische Methoden. Berlin: Springer.

Kumar, V., Peterson, A., Leone, R. P. (2013). Defining, Measuring and Managing Business Reference Value. Journal of Marketing. Vol. 77, No 1.

Niemczyk, A. (2015), The Application of Path Modelling in the Analysis of Consumer Behaviour in the Cultural Tourism Market, Economics and Sociology, Vol. 7, No 1, 2014, pp. 204-216. DOI: 10.14254/2071-789X.2014/7-1/18

Niemczyk, A. (2015), Family Decisions on the Tourist Market, Economics and Sociology, Vol. 8, No 3, pp. 272-283. DOI: 10.14254/2071-789X.2015/8-3/19

Sedláková, D., Heřmanová, E., Indrová, J. (2014). Tourist Card as a Tool of Destination Management. Czech Hospitality and Tourism Papers. Vol. 10, No 23.

Shah, D., Kumar, V. (2012). The Dark Side of Cross-Selling. Harvard Business Review. December 2012.

Short, T. Strategies for Satisfying Walked Hotel Guests IndustryView 2014 [online]. 2014 [Accessed 2015-05-30]. Available at: http://www.softwareadvice.com/hotel-management/industryview/strategies-for-walked-guests-2014/

Streimikiene, D., Bilan, Y. (2015) Review of rural tourism development theories, Transformations in Business and Economics, 14 (2), pp. 21-34

Český statistický úrad (2015). Využití lůžek a pokojů v hotelech a podobných ubytovacích zařízeních v ČR a krajích (NUTS III). Cestovní ruch - časové řady [online]. Available at: https://www.czso.cz/csu/czso/cru_cr

Vaško, M., Abrhám, J. (2015). Issues of Secure and Sustainable E-Tourism: Case of the Czech Republic. Journal of Security and Sustainability Issues. Vol. 5, No 2, pp. 137-148 